NASA Technical Memorandum 86424

NASA-TM-8642419860004423

\title{
Effects of Digital Altimetry on Pilot Workload
}

Randall L. Harris, Sr., and Bobby J. Glover

NOVEMBER 1985

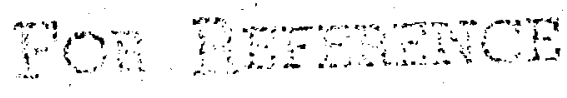

a $\quad$ and and and

MOT TO EE TAKEA FHOH THS SOM 
NASA Technical Memorandum 86424

\section{Effects of Digital Altimetry on Pilot Workload}

Randall L. Harris, Sr.

Langley Research Center

Hampton, Virginia

Bobby J. Glover

PRC Kentron, Inc.

Hampton, Virginia

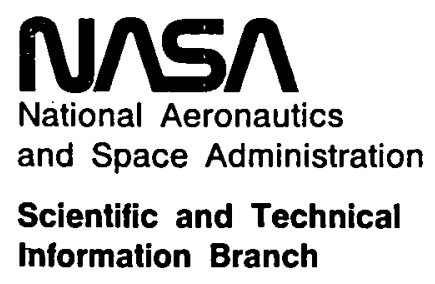


A series of VOR-DME instrument landing approaches was flown in the Langley DC-9 Full-Workload Simulator to compare pilot performance, scan behavior, and workload when using a counter-drum-pointer altimeter (CDPA) and a digital altimeter (DA) . Six pilots executed two sets of instrument landing approaches, with a CDPA on one set and $a D A$ on the other set. The DA consisted of five, seven-segment LED digits, 0.28 inch high. Pilot scanning data were collected with an oculometer system. The oculometer data were reduced to dwell percentages, average dwell times, transition matrices, and dwell time histograms and were statistically analyzed. In addition to the pilot scanning parameters, flight performance and subjective opinion data were collected and evaluated. Based upon the results of these tests the following conclusions were drawn. The processes of gathering information from the CDPA and the $D A$ are different. The DA imposes a higher mental workload than the CDPA for a VOR-DME type landing approach. Mental processing of altimeter data after looking away from the altimeter was more evident with the DA than with the CDPA. And finally, all the pilots preferred the CDPA over the DA.

\section{INTRODUCTION}

Altitude data are one of the most significant pieces of information needed by a pilot during every phase of flight. Misreading of altimeter information can lead to undesirable or dangerous situations. Consequently, several designs have been studied in an attempt to find a better altimeter. Tests conducted and reports written on the subject are numerous. For example, reference 1 cites over 70 reports and reference 2 cites over 100 reports of altimeter-related research. It should be noted that most of the tests were conducted by showing the test subjects a picture of an altimeter and asking them to respond with the displayed altitude. Response time and accuracy measures were recorded. However, this is not the manner in which altimeters are used in the aircraft.

With the opportunity for improving information transfer provided by the proliferation of advanced display media usage in the aircraft cockpits of today (ref. 3), it is desirable to define what information pilots need and the format that is most efficient at transferring this information. The use of digital information is especially appealing because it has become relatively simple to output alphanumeric data to a cathode-ray tube (CRT) or other electronic display device. However, it is not at all clear that a digital format would result in the most efficient transfer of information to the pilot. As part of a series of experiments to investigate the effects of advanced display formats and display media, the present piloted simulation study was conducted to compare the effects of a digital altimeter (DA) and a counter-drum-pointer altimeter (CDPA) on pilot scanning behavior and workload, flight performance, and pilot subjective opinion.

TESTS AND EQUIPMENT

A series of tests was conducted with the Langley DC-9 Full-Workload simulator (fig. 1). The cockpit was representative of a twin-engine, medium-size, 
commercial jet transport. The instrument panel layout and types of instruments used are typical of those found in most airliner configurations (figs. 1 and 2). The two altimeters used in this study are shown in figures 3 and 4 . The one in figure 3 is a counter-drum-pointer altimeter (CDPA). The counter moves much like an odometer and indicates the altitude in thousands of feet. The drum rotates like the tenths of miles on an odometer and indicates altitude in hundreds of feet. The pointer is a meter movement also representing the altitude in hundreds of feet relative to thousands. The digital altimeter (DA), shown in figure 4, consisted of five, red, seven-segment LED digits, 0.28 inch high. Based upon preliminary tests the units digit of the DA was kept at zero thereby limiting the DA resolution to feet.

Six pilots with a variety of experience levels were used as test subjects. These subjects included a NASA test pilot, two FAA employees experienced in jet transport or twin-engine aircraft flying, a U.S. Air Force turboprop transport pilot, a former U.S. Air Force jet fighter pilot with jet transport experience, and a commercial jet transport pilot. Each pilot executed two sets of landing approaches, with the CDPA on one set and the DA on the other set. Each set involved at least five landing approaches. The piloting task was a VOR-DME (VHF omnidirectional rangedistance measuring equipment) landing approach with altitude constraints imposed at six specified locations along with straight-in portion of the approach. Figure 5 shows the approach plate used to define the task for the pilot. Each approach began 5 miles abreast of the runway, at an altitude of 6000 feet, heading outbound on a downwind leg. The pilots were given appropriate altitude and heading clearances to bring the aircraft to a position 12 miles from the airport at an altitude of 3000 feet and at the correct heading to intercept the approach path. The landing approach was to be ended and missed approach procedures were to be executed as the aircraft passed over the end of the runway. The first pilot executed his missed approach earlier in the approach; therefore, a portion of his altitude performance data had to be omitted. One of the authors (with simulator experience) served as a copilot for these landing approaches. The copilot's function was to make any configuration changes requested by the pilot and to give air traffic control clearances (altitude and heading) at predetermined positions in the flight scenario to place the aircraft at the proper final approach location. Each pilot then flew the approach, attempting to meet the altitude assignments listed in the approach plate in figure 5 . This particular approach was selected because it was believed that it would maximize the use of the altimeter and provide a better evaluation of the two formats. At least five practice approaches were performed by each pilot with the DA to familiarize him with the new altimeter and the VOR-DME approach. Each approach lasted approximately 13 minutes. The length of each testing session was limited to 2 hours to prevent fatigue effects. Because of altimeter changeover times, only one altimeter was used in each session.

Pilot scan behavior data were collected with an oculometer system shown in figures 2 and 6 and described in reference 4 . These data, which consisted of $\mathrm{x}$ and $\mathrm{y}$ coordinates and pupil diameter, were stored 32 times a second, along with aircraft parameters, on magnetic tape for data analysis. The oculometer data were reduced to dwell percentages, average dwell times, transition matrices, and dwell time histograms and were statistically analyzed. In addition to these quantitative data, pilot subjective opinion data were collected in the form of a questionnaire (table I). Pertinent ad-lib comments made by the pilot test subjects during the course of the testing sessions were also noted. 


\section{RESULTS}

\section{Scanning Behavior}

Figures $7(a)$ and $7(b)$ show a schematic of the instrument panel, on which transition paths between instruments are depicted for the DA and CDPA, respectively; the average dwell percentages (total time looking at an instrument divided by the total time available) and average dwell times (total time looking at an instrument divided by the total number of times the instrument was looked at) on each instrument are also shown for the two test conditions. The width of a transition path is proportional to the number of two-way transitions (the total number of times the pilot looked from one instrument to another and vice versa). Two-sample $t$ tests (ref. 5) were used to compare equivalent scan parameters. The significant differences between parameters in figure 7 are indicated by a symbol representing the significance level. The dwell percentage and average dwell time on the altimeter were not statistically different for the DA compared with the CDPA. There was, however, an increase in the percentage of transitions to the DA from the attitude indicator. There was also an increase in the percentage of transitions to the vertical speed indicator from the attitude indicator, horizontal situation indicator, and altimeter. These data indicate a general shift of attention to altitude information when the DA is used.

Figures 8 and 9 are a comparison of the CDPA and DA monitoring and controlling dwell time histograms. The peak in the monitoring histogram (fig. 8) of the DA is higher than the peak of the CDPA. This higher peak indicates that either the pilot gets the altitude information more quickly from the digital format than from the CDPA format or that he gets more information from the CDPA such as altitude and altitude rate. This latter explanation would account for the increased number of transitions to the rate-of-climb indicator when the DA was used. A KolomogorovSmirnov test (ref. 6) of these data showed that the DA and the CDPA monitoring dwell histograms were significantly different at the 1-percent level and that the control input dwell histograms were significantly different at the 8-percent level. There is no difference in the control input dwell histograms of figure 9.

Further data analysis was performed to determine if other effects were present such as an increase in the length of the dwell time following the altimeter dwell that would indicate that additional mental processes were needed to evaluate altitude information. Since about two-thirds of all transitions from the altimeter were back to the attitude indicator, it was decided that attitude dwell histograms would be constructed based upon whether the previous look was on the altimeter. Figures 10 and 11 are the resulting monitoring and pitch controlling attitude dwell histograms. As depicted by these histograms, attitude dwells are longer following the DA looks than those following CDPA looks. On the average when making control inputs (fig. 11), the attitude dwells are 0.2 second longer after DA looks than CDPA looks.

Pitch control inputs were further analyzed to determine the time during the attitude dwell at which the control input was made. The histogram plot in figure 12 shows that the control input following a DA look occurred over 0.1 second later on the average than a control input following a CDPA look. Therefore, the control inputs were made faster after having looked at the CDPA than the DA. 


\section{Flight Performance}

Several aircraft state and control parameters were analyzed to detect differences in flight performance. Parameters evaluated were aircraft attitudes, attitude rates, altitude assignments, VOR ground track errors, airspeed, rate of sink, and pitch, roll, yaw, and throttle control inputs. Consistent trends between altimeters were not found in any of these parameters to indicate that either altimeter would lead to better performance. The bar graph in figure 13 presents the pilots' ability to meet the altitude conditions of the VOR-DME approach. The mean is represented by the height of the bar, and the standard deviation is indicated by the height of the $T$ above the bar. Data from one of the pilots were deleted at 0.5 nautical mile because he has already begun his missed approach procedure climb. Standard two-sample $t$ tests and $F$ tests (ref. 5) did not indicate differences even at the 10-percent level in the means and standard deviations of the altitudes associated with either altimeter. Therefore, for the overall workload of this task, the pilot could perform the approach equally well regardless of the type of altimeter used.

\section{Pilots' Comments}

The pilots were asked to fill out a questionnaire (table I) after their last simulator run. The questions were designed to elicit their thoughts about their workload, confidence, and usefulness of the two altimeters. The last question gave the pilots an opportunity to make any further comments about the altimeters used in the tests. In addition to these formal questions, any comments made during the performance of the tests were also noted for later evaluation.

In general, pilots' comments about the DA were negative. All the pilots preferred the CDPA because it was "easier to use" than the DA. First, they did not have an adequate feel for correct altitude to initiate a smooth leveling-out maneuver when changing altitude with the DA; however, with the CDPA they could easily time the control inputs based upon the position of the needle and the rate at which it was moving toward the desired altitude. Second, some of the comments indicated that the pilots had more difficulty forming a mental picture of their altitude when using the DA as compared with the CDPA. The DA almost always indicated an altitude different from the assigned altitude (this was very frustrating to some of the pilots even if the distance was only 10 feet). Third, the pilots had to perform mental arithmetic practically every time they looked at the DA (i.e., they had to read the altitude, and compare it with the desired altitude to get the altitude error).

With all these negative comments, however, five of the pilots thought that the type of altimeter did not affect either their ability to fly the approach or their scan behavior. However, one situation in which they thought that the CDPA would be better than the DA would be in a rapid climb or descent. They did not feel that the "flickering digits" would provide good altitude rate information for this maneuver.

Comments noted during the simulator runs indicated that the pilots approved of the decision to display the altitude to the nearest 10 feet. Any larger increment (e.g., 50 or 100 feet) would impact the required accuracy, and any smaller 
increments (e.g., I foot) would make the display flicker too much. A color other than red would be desirable since red is generally reserved for emergency situations (other colors were not used in these tests).

\section{DISCUSSION}

Parameters such as average dwell times and flight performance variables did not show differences for the $D A$ and CDPA. Even though comments were negative concerning the $D A$, the pilots indicated that they could accomplish the instrument landing approach task with either altimeter. These results illustrate the fact that average dwell times, flying performance, and pilot comments by themselves are not always sufficient to evaluate the effects of displays on pilot workload. The Kolmogorov-Smirnov test showed that the DA and CDPA dwell histograms were statistically different. This difference indicates that even though the average dwell times were the same for the two altimeters, the processes of acquiring information from the altimeters were different.

For the task of a VOR-DME instrument landing approach, the DA imposes a higher mental workload. The conclusion of a higher workload is warranted by (1) the trend of more transitions to altitude and altitude rate information (altimeter and vertical speed displays), (2) higher percent usage of the vertical speed indicator, and (3) pilot comments such as lack of an adequate mental picture and increased mental calculations with the DA.

The increase in attitude dwell time, after looking at the digital altimeter, along with pilot comments that they were having to make mental arithmetic operations with the $D A$ shows that after looking at the $D A$, the pilots were still mentally processing the information obtained from the DA even though they had transitioned back to another instrument (attitude indicator in this case). Indications are that the time spent looking at an instrument (dwell time) is not the entire picture of the workload imposed by that instrument. Future research should include evaluations of delayed processing effects on scanning behavior and workload.

\section{CONCLUDING REMARKS}

A series of VOR-DME instrument landing approaches was flown in the Langley DC-9 Full-Workload Simulator to compare pilot performance, scan behavior, and work load when using a counter-drum-pointer altimeter (CDPA) and a digital altimeter (DA). The overall workload was low enough in these tests that the flight performance was not affected by the type of altimeter. However, based upon these tests it is evident that the digital altimeter imposes a higher mental workload for a VOR-DME type of approach.

The processes of gathering information from the digital altimeter and the counter-drum-pointer altimeter are different. The pilots have to supplement the digital altimeter information with altitude rate information from the vertical speed indicator to accomplish the instrument landing approach task. Mental processing of altitude information, even after transitioning back to the attitude indicator is more evident with the digital altimeter than with the counter-drumpointer altimeter. Pilot subjective opinion data corroborate the objective data 
demonstrating that the digital altimeter increases pilot workload over that of the counter-drum-pointer altimeter.

NASA Langley Research Center

Hampton, VA 23665-5225

June 24,1985

\section{REFERENCES}

1. Schum, David A.; Robertson, John R.; and Matheny, W. Guy: Altimeter Display and Hardware Development, 1903 - 1960. ASD-TDR-63-288, U.S. Air Force, May 1963. (Available from DTIC as AD 408 989.)

2. Shrager, Jack J.: Altimetry Display Study: Part Three - Review of R\&D on Display Readability. FAA-RD-72-46, III, May 1972. (Available from DTIC as $A D 751021$ ).

3. Boucek, G. P.; Pfaff, T. A.; and Smith, W. D.: Methods and Instrumentation for Evaluation of Advanced Displays and Pilot Performance. Second Aerospace Behavioral Engineering Technology Conference Proceedings, P-132, Soc. Automot. Eng., Inc., 1983, pp. 211-218. (Available as SAE Paper 831462.)

4. Spady, Amos A., Jr.: Airline Pilot Scan Patterns During Simulated ILS Approaches. NASA TP-1250, 1978.

5. Hays, William L.: Statistics for the Social Sciences, Second ed. Holt, Rinehart and Winston, Inc., c.1973.

6. Siegel, Sidney: Nonparametric Statistics for the Behavioral Sciences. McGraw-Hill Book Co., Inc., 1956. 
1. Which altimeter gave you more confidence while performing the VOR-DME approaches? Why?

2. Was there a difference in your workload with either of the altimeters? If so, why?

3. Did you scan the instruments differently with the altimeters? If yes, how differently and was it an acceptable difference?

4. Did the type of altimeter affect your ability to make the VOR-DME approaches? If so, in what way?

5. Could you foresee any flight situation where you would prefer one altimeter over the other? If so, why?

\footnotetext{
6. Would it make a difference to you which altimeter was installed in the airplane on your next flight? If so, which would you prefer and why?
}

7. Please make any comments on either altimeter that have not been covered in the above questions on the back of this paper. 


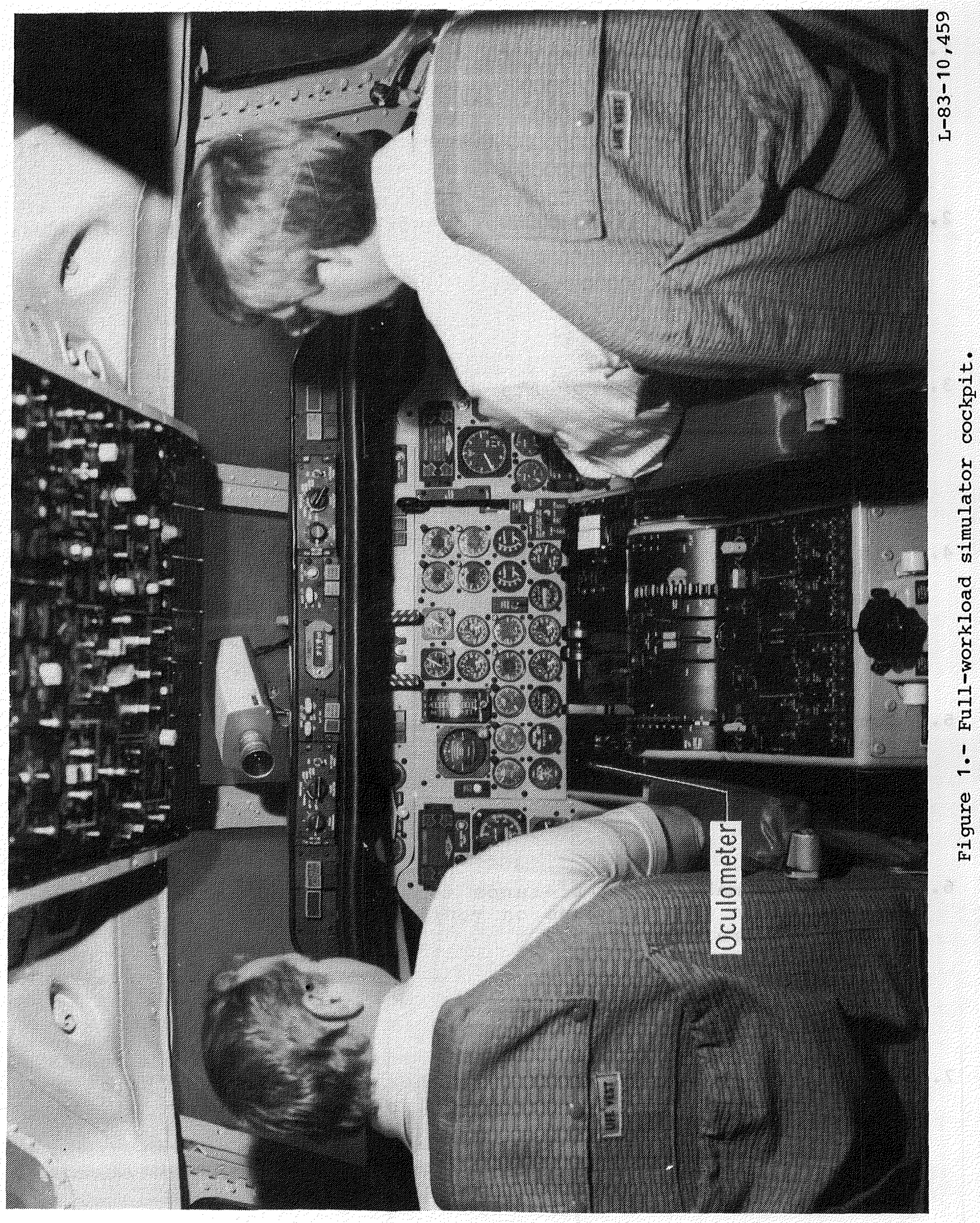




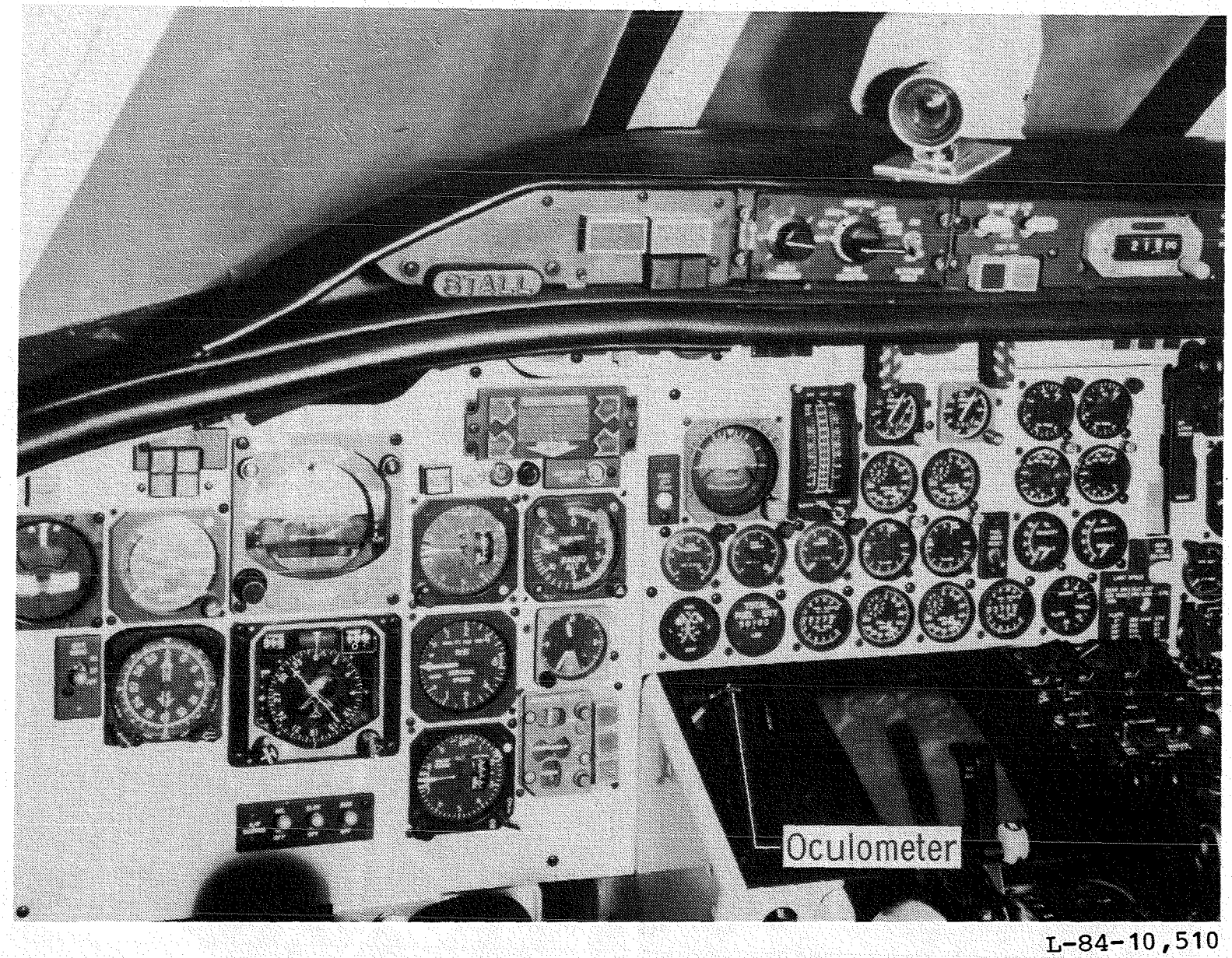

Figure 2.- Full-workload simulator instrument panel. 


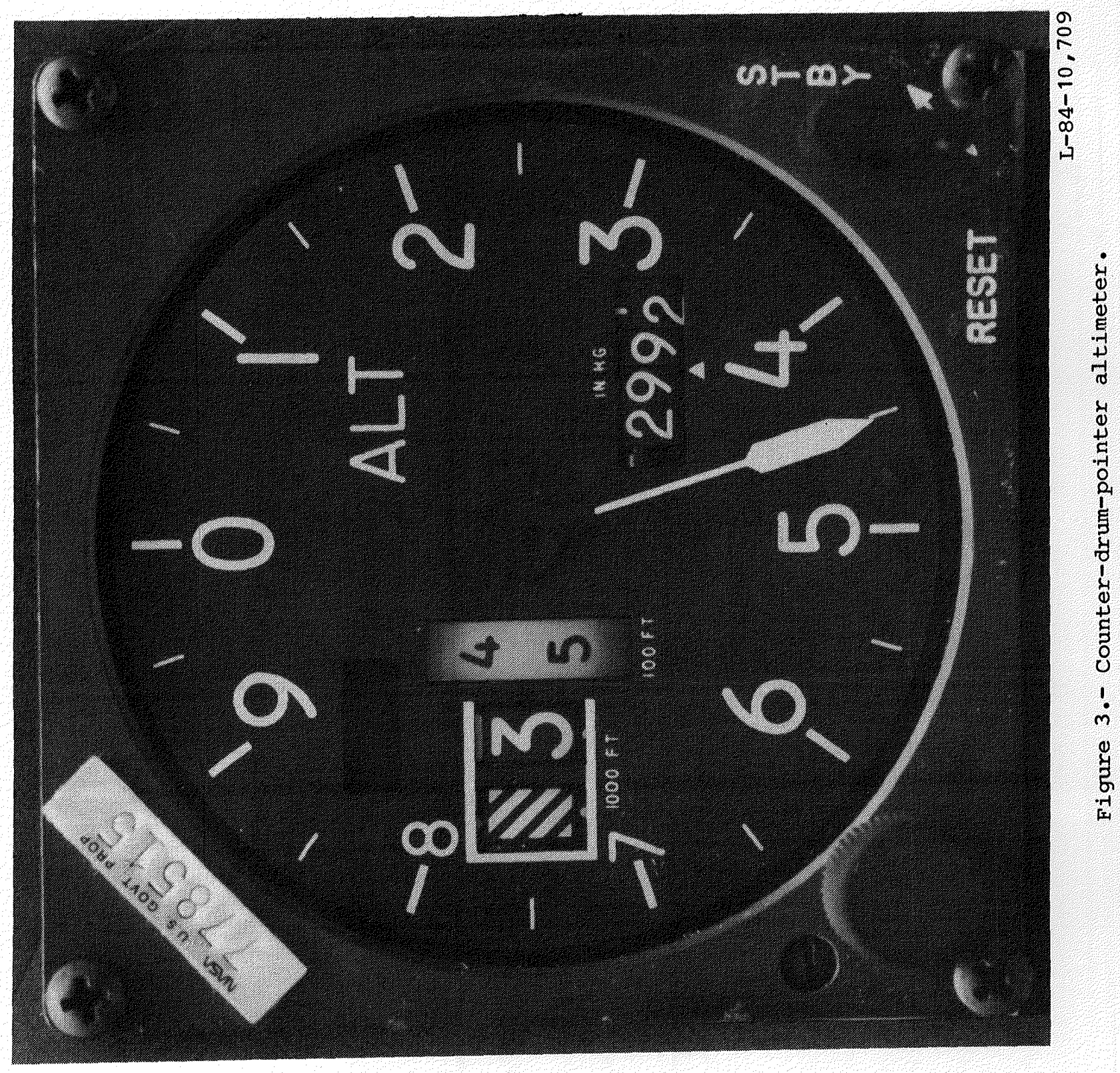




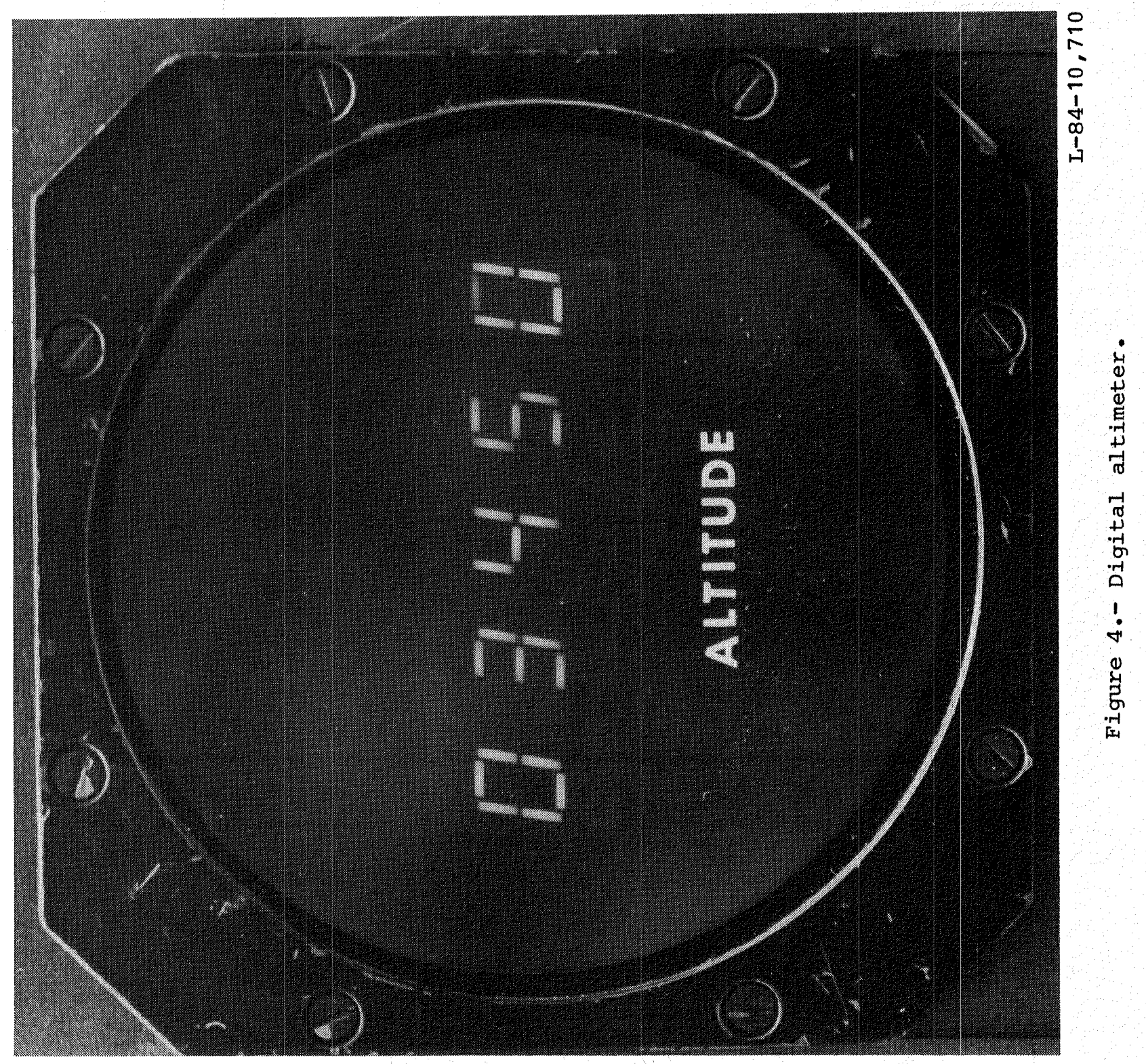




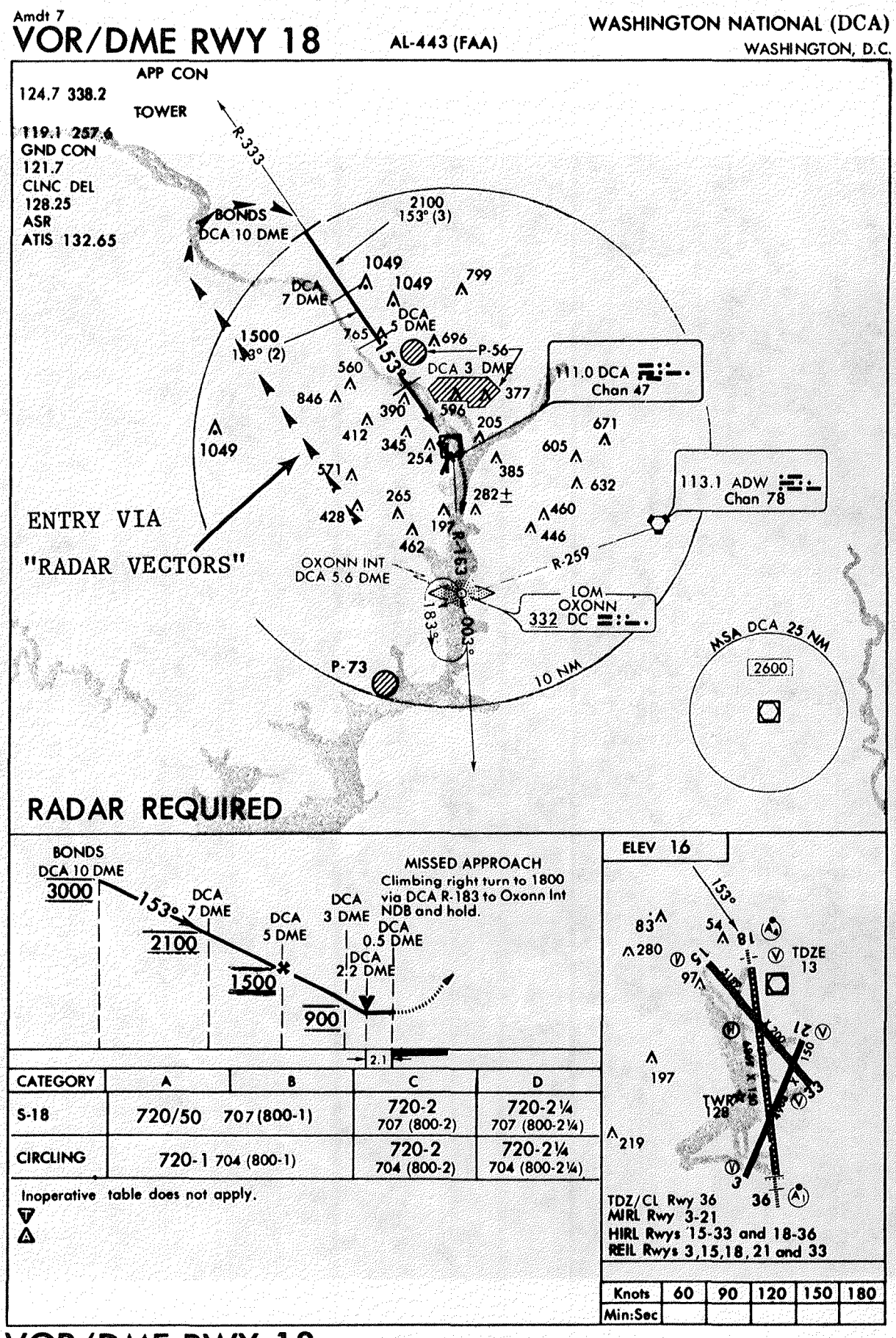

\section{VOR/DME RWY $18 \quad \frac{38^{\circ} 51^{\prime} \mathrm{N}-77^{\circ} 02^{\prime} \mathrm{W}}{289^{2}}$}

Figure 5.- Modified approach plate as used in this study. 


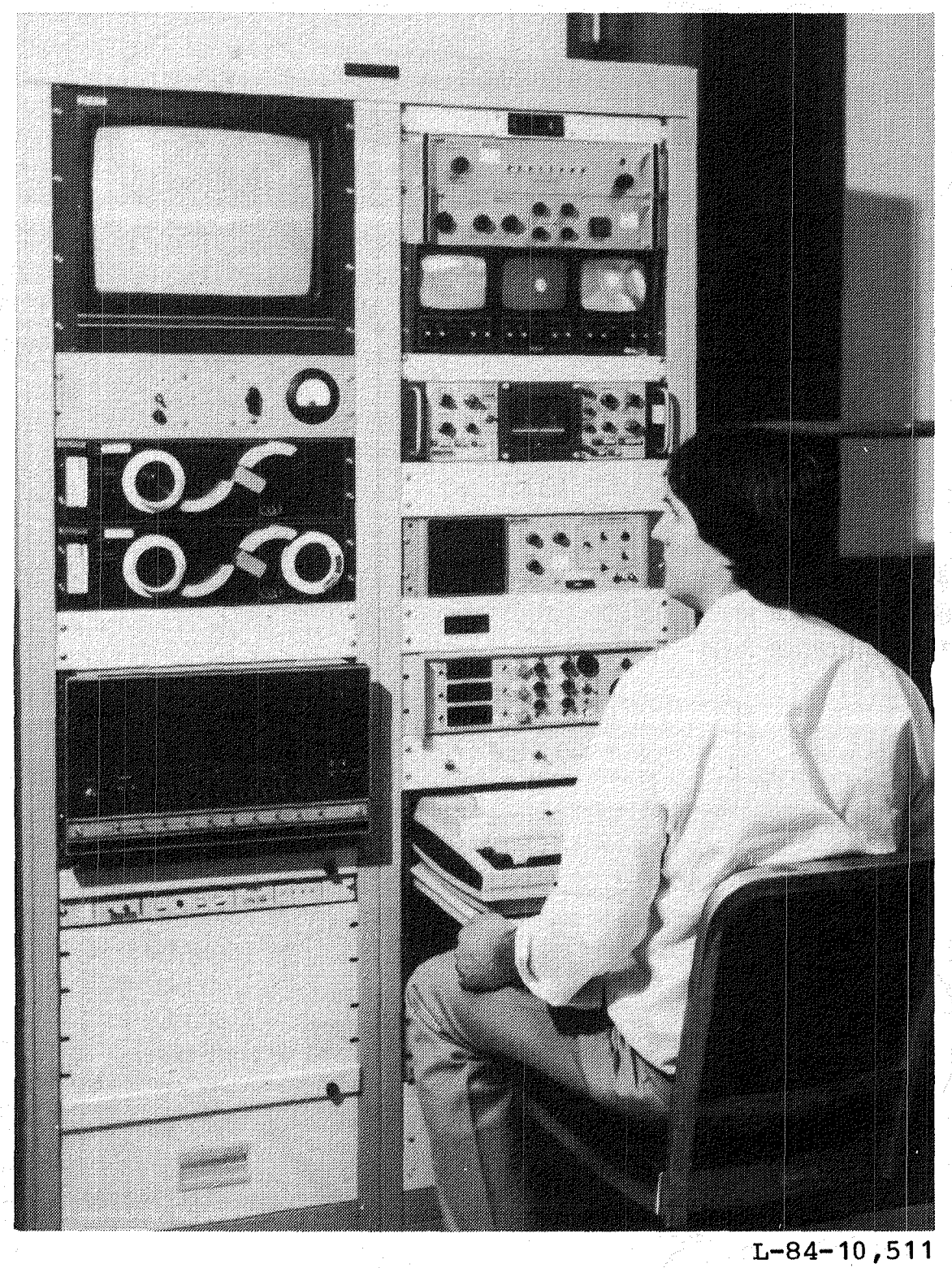

Figure 6.- Oculometer equipment rack. 

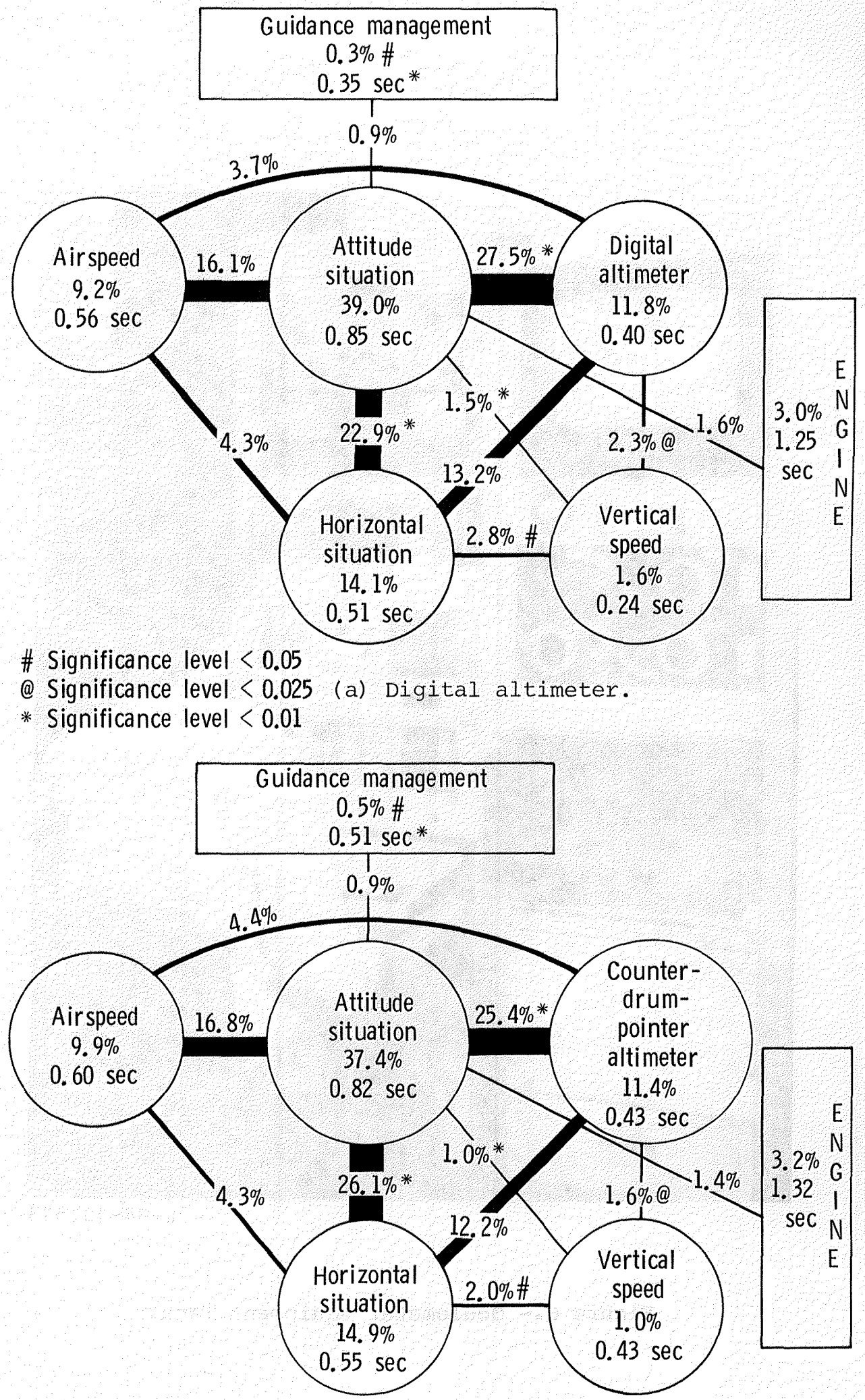

(b) Counter-drum-pointer altimeter.

Figure 7.- Scan behavior comparison. 


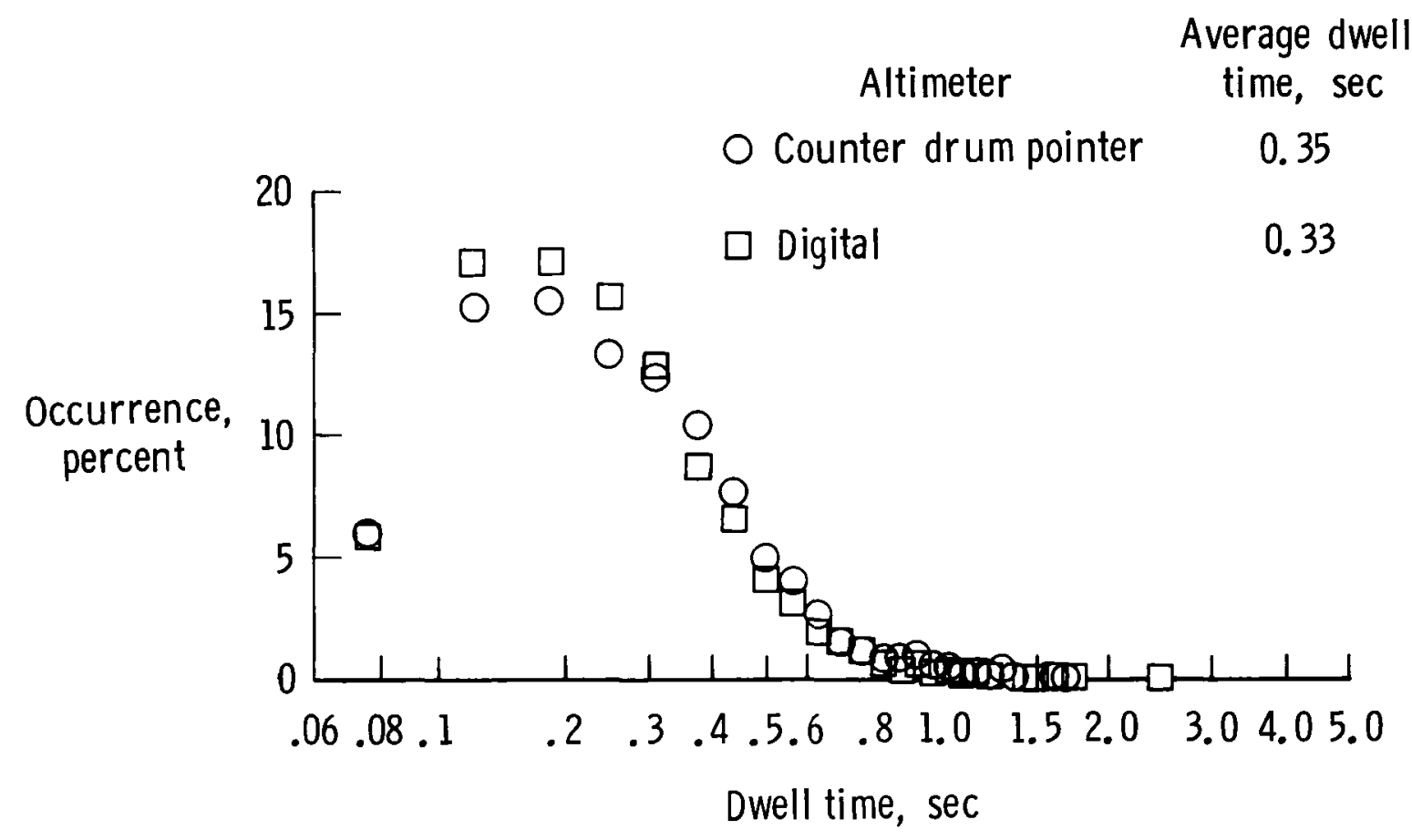

Figure 8.- Altitude monitorıng dwell histogram.

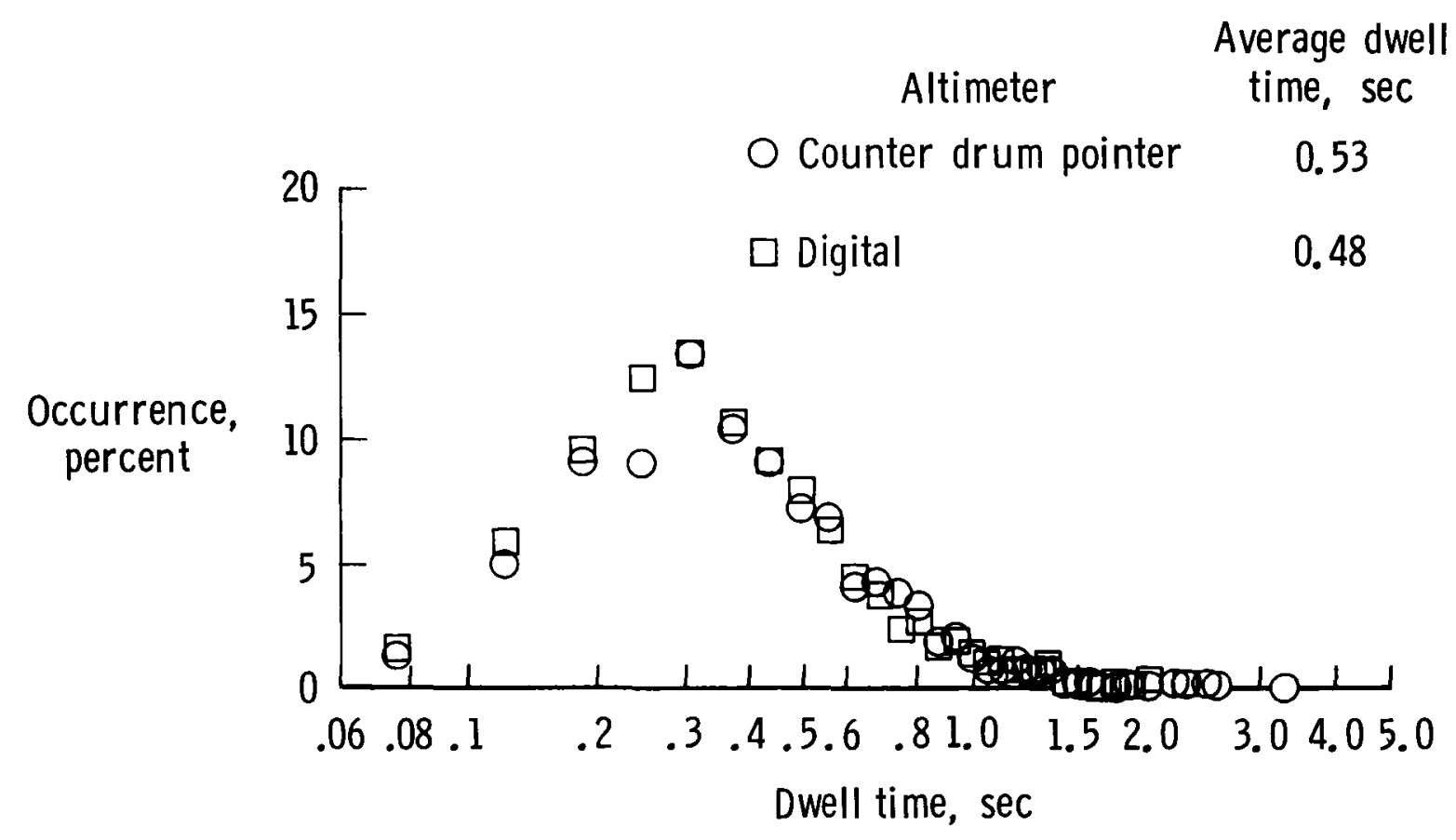

Fıgure 9.- Altitude control input dwell histogram. 


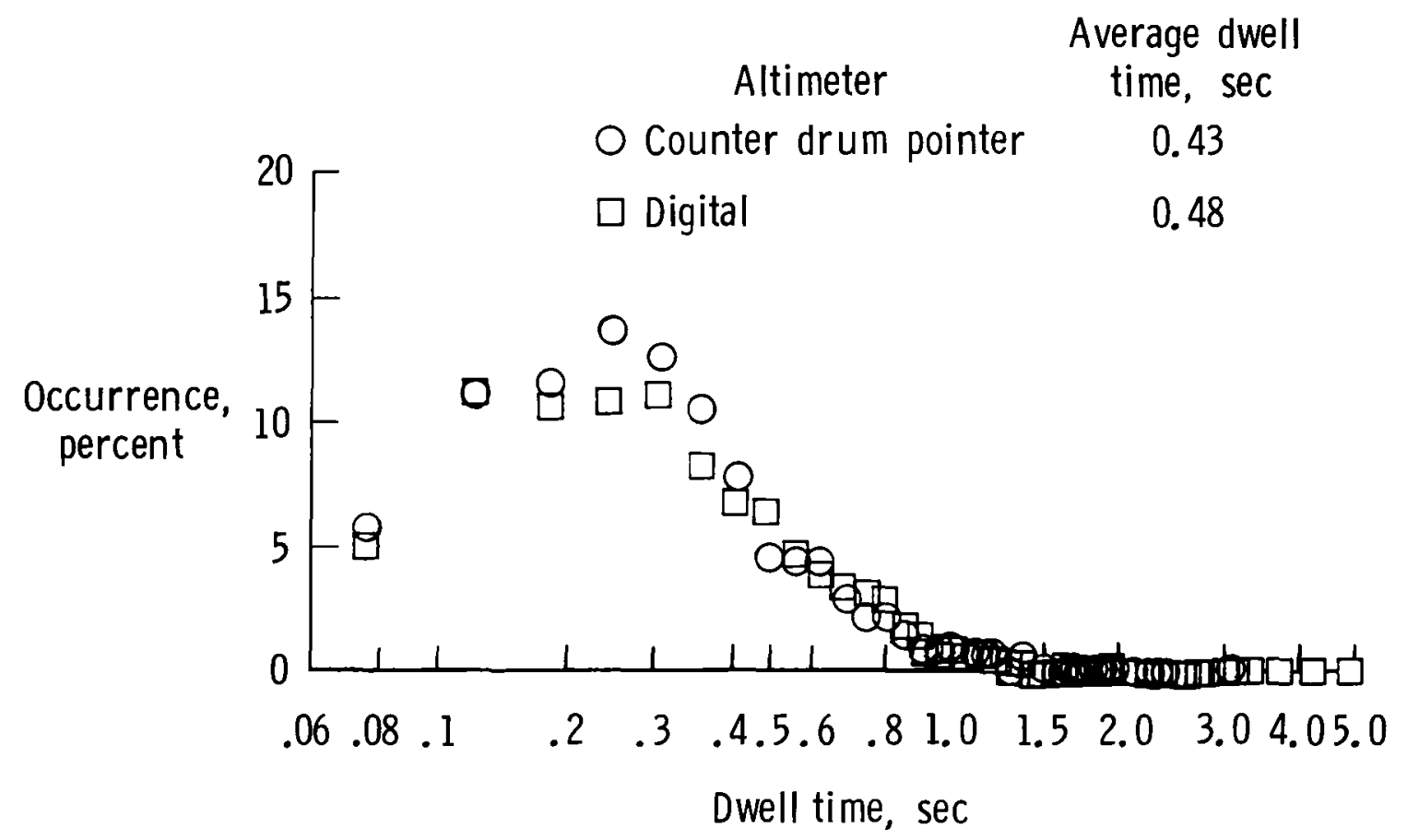

Figure 10.- Attıtude monıtorıng dwell histogram after lookıng at altımeter.

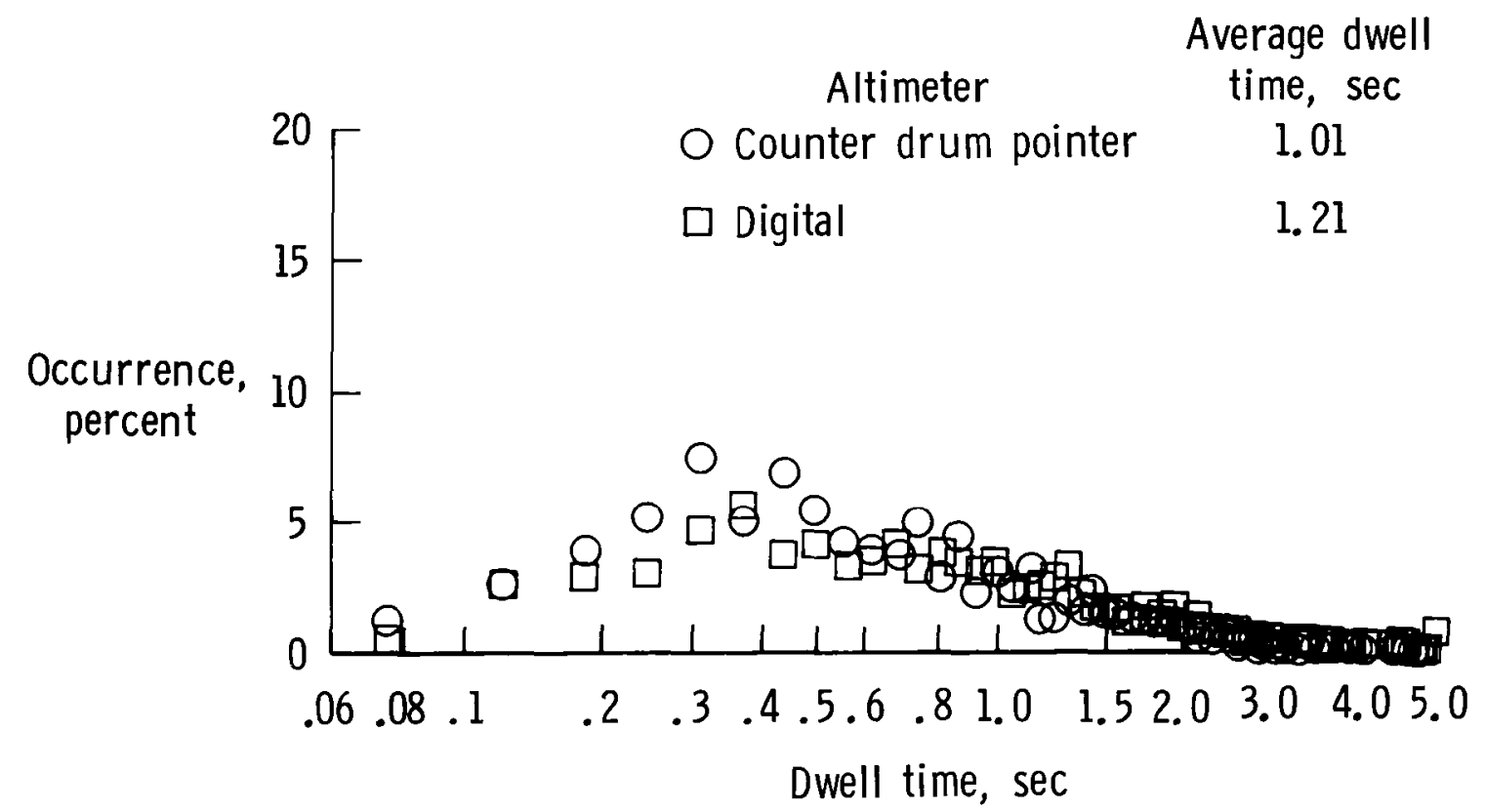

Figure 11.- Attıtude control input dwell histogram after lookıng at altımeter. 


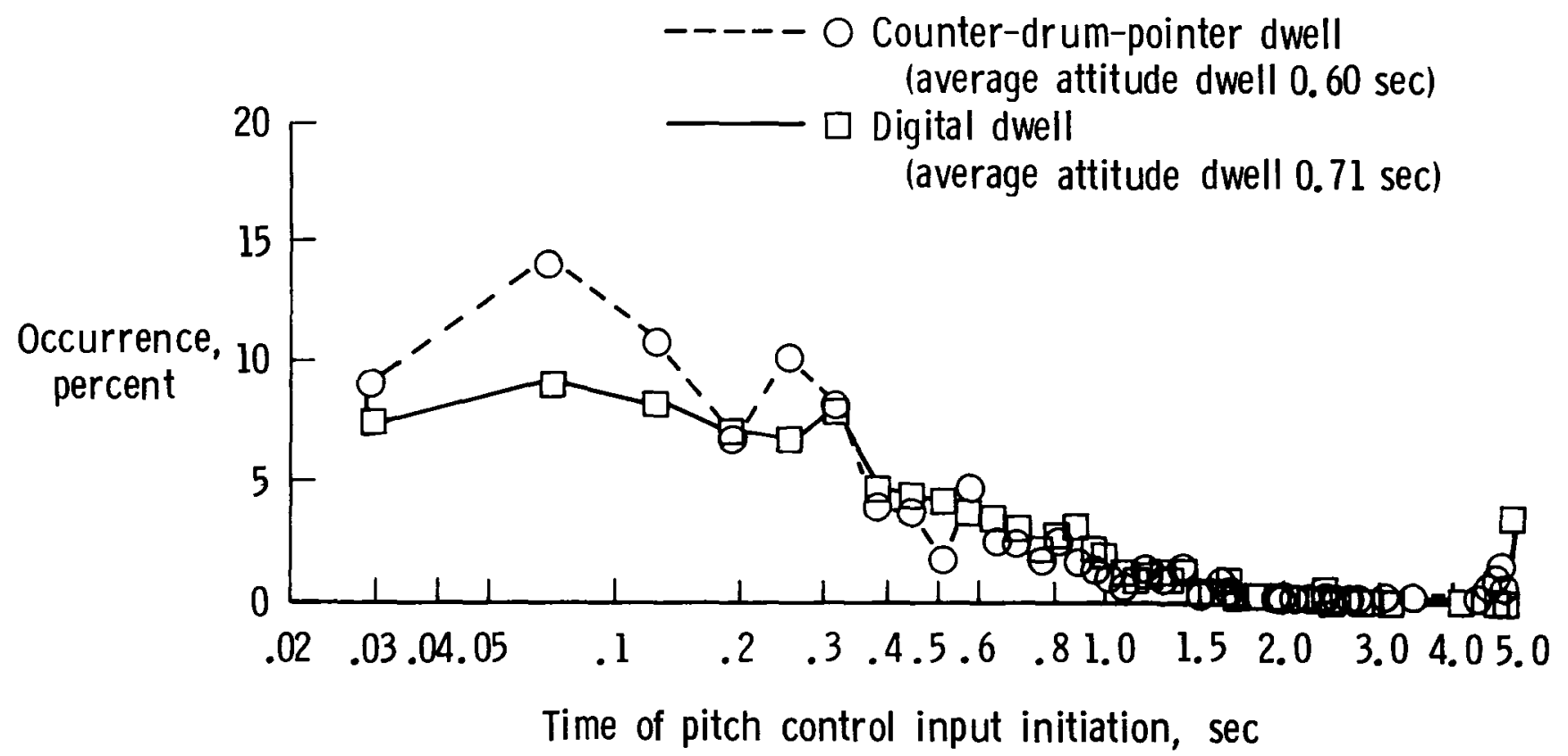

Figure 12.- Pitch control input timing during attitude dwell following attıtude dwell.

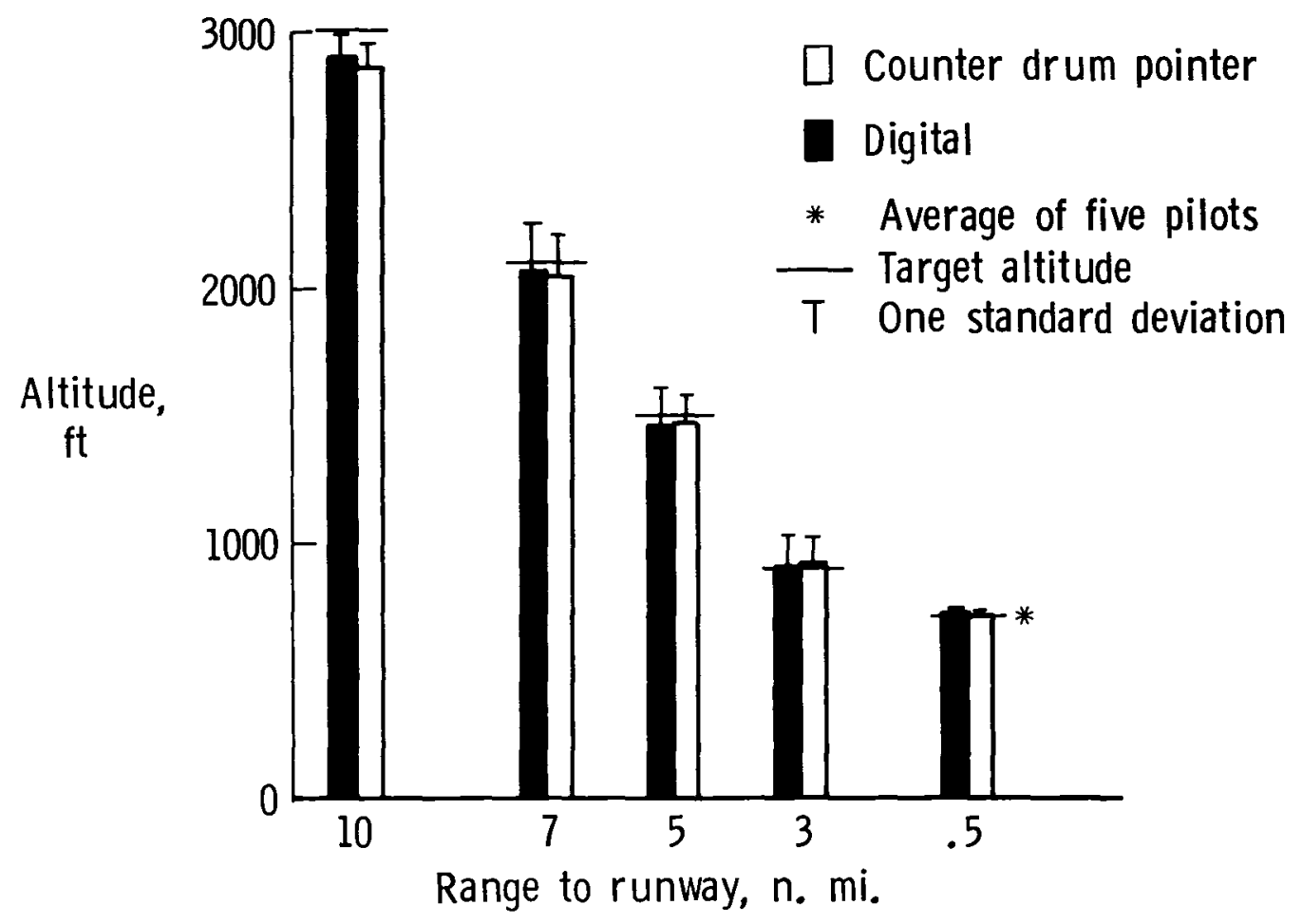

Figure 13.- Altıtude performance during landing approach. 


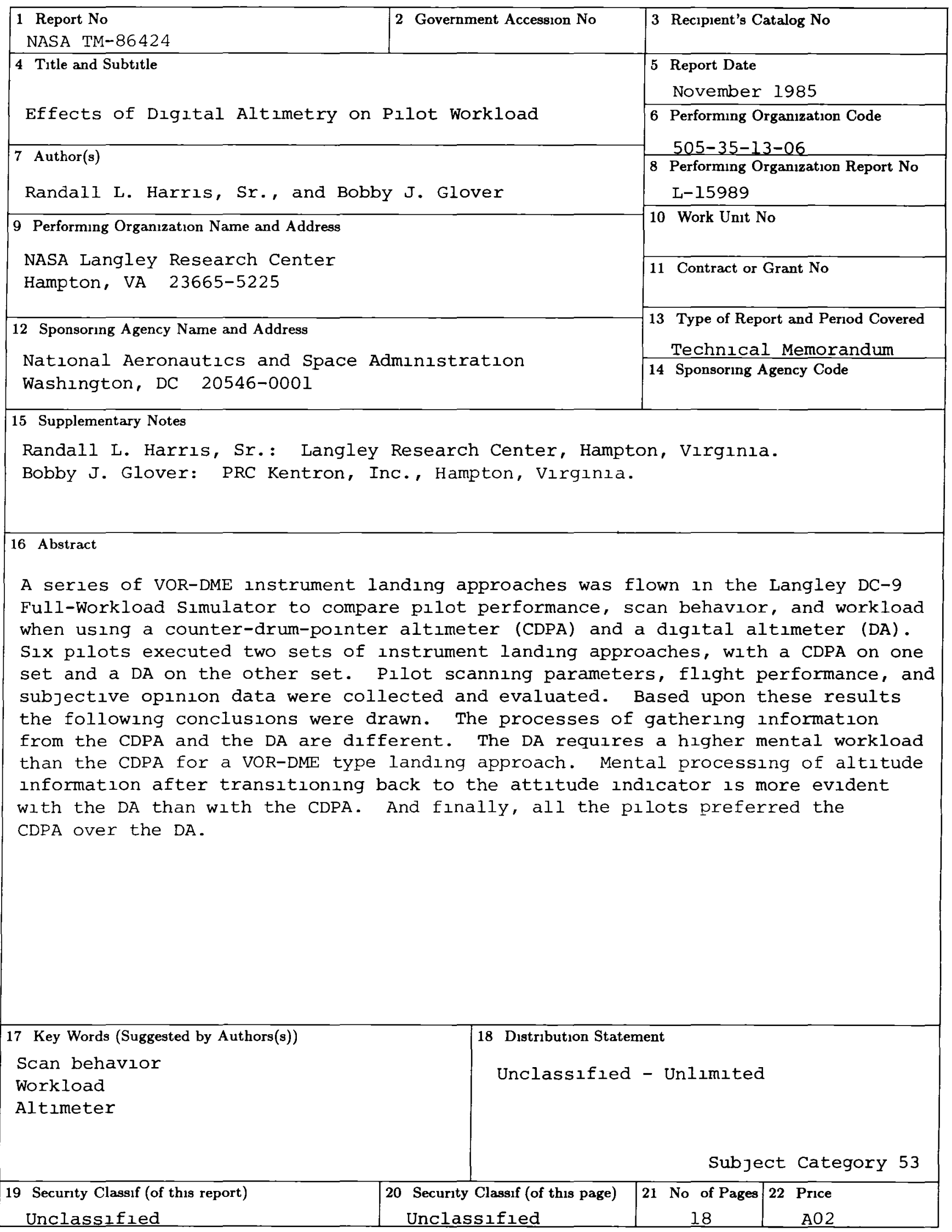


End of Document 